\title{
To Study Antibacterial Activity of Allium Sativum, Zingiber Officinale and Allium Cepa by Kirby-Bauer Method
}

\author{
Mahmood Khan Yousufi \\ Department of Microbiology Jawaharlal Nehru College, Bhopal (M.P.) India
}

\begin{abstract}
Allium sativum, Zingiber officinale and Allium cepa are often used in different systems of medicines like ayurveda and Unani. All these three plants contain chemicals which can inhibit the growth of microbes. These chemicals actually bear properties which make them suitable to be utilized in different medicines. In the present investigation, the effectiveness of chloroform, ethanol and aqueous extracts of A. sativum, Z. officinale and A. cepa was detected against Escherichia coli, Klebsiella pneumoniae, Pseudomonas aeruginosa, Staphylococcus aureus, Enterococcus faecalis, Proteus mirabilis and Salmonella spp. along with a comparison with an antibiotic, streptomycin. The method adopted in the present study was the Kirby-Bauer method. The maximum antimicrobial activity was exhibited by chloroform extract of A. sativum i.e.24mm against E.coli whereas the minimum antimicrobial activity was exhibited by aqueous extract of A. cepa 05mm against Enterococcus faecalis.
\end{abstract}

Keywords: Allium sativum, Zingiber officinale, Allium cepa, Antibacterial activity, Kirby- Bauer.

\section{Introduction}

Garlic (Hindi-Lahsun), botanical name "Allium sativum" is an economically important plant. It belongs to the family Liliaceae. The bulbs of Garlic are used as condiments. The juice extracted from garlic bulbs is also medicinally very useful has been described by Agarwal [1], 1999. Ginger (Hindi- Adrak), botanical name "Zingiber officinale" belongs to the family Zingiberaceae. Ginger is native of South East Asia, which has been used for long in India and China. Ginger cultivation is done mainly in the states of Kerala, Bengal, Maharashtra, Himachal pradesh, Madhya Pradesh and Uttar Pradesh of India. Ginger is perennial herb which grown in moist places by rhizome. Rhizome is of economic importance in which starch, gum, oleoresin and essential oil is found, was stated by Agarwal[1], 1999. Ginger is also a stimulant. Ginger is crushed to yield a juice which when mixed with honey is used for the treatment of colic pain or diarrhea, as medicine. Onion (Hindi-Piyaz) botanical name : "Allium cepa" belongs to the family liliaceae or Alliaceae. Oil can be extracted from onion bulbs was reported by Agarwal[1]), 1999. The Onion bulb paste and oil are mixed and applied on injured body parts which provide relief from inflammation. Onion has stimulant, diuretic and expectorant properties. Hence it is also used as medicine. The above information gives a clear view of medicinal values of $A$. sativum, Z. officinale and A. cepa. Kartal[10] et al., 2003 studied In vitro antibacterial, antifungal and antioxidant activity of the essential oil and methanol extract of herbal part and callus culture of Satureja hortensis. Antimicrobial activity of essential oil and other plant extracts was investigated by Hammer[8] et al. 1999. Antimicrobial activity of some important medicinal plant against plant and human pathogen was determined by Malesh[12] and Satish,2008. In 1985, Ramesh[17] et al., established that in modern age most of the medicinal therapies involve use of plant extracts. However, it has been studied by Elsamma Thomas[7] et al., 1999 that majority of angiospermic plants, are rich in chemicals which can be used in treating diseases like diarrhea, dysentery, skin infections, colic disorders, rheumatoid, arthritis etc. In addition to this Muraganandam[14] et al., 2000 isolated an oil from the leaves of Wrightia tinctoria, which with coconut oil base are used for the treatment of psoriasis. Bibita[5] et al.,2002 investigated on antibacterial activity of different plant extracts. Antimicrobial Activity of some medicinal plants against Candida albicans was studied by Hassawi[9] and Kharma, 2006. Kelmanson[11] and Staden, 2000 detected certain medicinal plants with antimicrobial activity. Mohan[13] et al., 2009 determined antimicrobial activity of selected Indian medicinal plants. In vitro antifungal activity of methanol extracts of some Indian medicinal against pathogenic yeasts and molds was investigated by Parekh[16] and Chanda 2008. Antibacterial and anticandidal efficacy of aqueous and alcoholic extracts of Neem (Azadirachta indica) was described by Nayak[15] et al., 2011. Antimicrobial activity and phytochemical analysis of selected Indian folk medicinal plants was studied by Shihabudeen[18] et.al., 2010.

The above evidences prove that plants are rich in various useful chemicals which can be utilized for treatment of different human diseases. Keeping the above evidences into consideration the present investigation was undertaken to assess the effectiveness of A. sativum, Z. officinale and A. cepa extracts on Escherichia coli, Klebsiella pneumoniae, Pseudomonas aeruginosa, Staphylococcus aureus, Enterococcus faecalis, Proteus mirabilis and Salmonella spp. Anbuganapathi[3] et al., 2000 used the Kirby-Bauer method to show the 
antibacterial and antifungal effect of the leaves of Wrightia tinctoria. The Kirby-Bauer [4] method used in the present study involves the principle of diffusion; hence it is also referred to as disc diffusion method (Ananthanarayana[2]), 1997. Kirby-Bauer method has also been described by Dubey[6] and Maheswari, 2002.

\section{Materials And Methods}

\subsection{Extract preparation:}

The fresh plant parts of A. sativum, Z. officinale and A. cepa were subjected to prepare chloroform, ethanol and aqueous extracts. For this purpose, the plant parts were washed and chopped into small pieces. Then $10 \mathrm{~g}$ of the material was crushed thoroughly in a blender with $100 \mathrm{ml}$ of extraction solvent (i.e. chloroform, ethanol or distilled water). Chloroform, ethanol and aqueous extracts of A. sativum, Z. officinale and A. cepa were extracted in a similar manner as described above. In the above prepared extracts filter paper discs were immersed, which were removed after 10 minutes and dried.

\subsection{Procedure:}

Nutrient agar medium was prepared and autoclaved at standard temperature of $121^{\circ} \mathrm{C}$, pressure of 15 psi (pounds per square inch) for a time period of 15 minutes. The autoclaved medium was aseptically transferred into pre sterilized Petri plates which are allowed to cool for solidification of medium. Now in aseptic conditions, on the solid agar surface, culture of Escherichia coli, Klebsiella pneumoniae., Pseudomonas aeruginosa, Staphylococcus aureus, Enterococcus faecalis, Proteus mirabilis and Salmonella spp. was inoculated by spread plate method in different Petri plates respectively. Thereafter, under aseptic conditions, saturated filter paper discs were placed on the inoculated solid agar surface. Similarly, commercially available streptomycin $(10 \mathrm{mcg})$ antibiotic discs were placed aseptically on the inoculated solid agar surface. The Petri plates were finally marked accordingly and incubated at $37^{\circ} \mathrm{C}$ for 48 hours.

\section{Results And Discussion}

The results obtained after incubation clearly exhibit that chloroform extracts of A. sativum, Z. officinale and A. cepa developed a maximum zone of inhibition i.e. $24 \mathrm{~mm}$ for E.coli, $22 \mathrm{~mm}$ for Staphylococcus aureus and $16 \mathrm{~mm}$ for Klebsiella pneumoniae (TABLE 1.), whereas the ethanol extracts of A. sativum, Z. officinale and A. cepa developed maximum zone of inhibition i.e. $23 \mathrm{~mm}$ for Klebsiella pneumoniae, $18 \mathrm{~mm}$ for S. aureus and $16 \mathrm{~mm}$ for E.coli (TABLE 2.) and aqueous extracts of A. sativum, Z. officinale and A. cepa developed maximum zone of inhibition i.e. $20 \mathrm{~mm}$ for Enterococcus faecalis., $19 \mathrm{~mm}$ Pseudomonas aeruginosa and $13 \mathrm{~mm}$ for E. coli (TABLE 3.). The zone of inhibition with Streptomycin antibiotic discs was obtained to be $25 \mathrm{~mm} \pm 2$.

Table-1. Showing inhibition zone diameter in $\mathbf{~ m m}$. with Chloroform extract.

\begin{tabular}{|l|c|c|c|}
\hline \multirow{2}{*}{ Name of culture } & \multicolumn{3}{|c|}{ Inhibition zone diameter in $\mathrm{mm}$} \\
\cline { 2 - 4 } & \multicolumn{3}{|c|}{ Chloroform extract } \\
\cline { 2 - 4 } & A. sativum & Z. officinale & A. cepa \\
\hline Escherichia coli & 24 & 13 & 14 \\
\hline Klebsiella pneumoniae & 21 & 16 & 16 \\
\hline Pseudomonas aeruginosa & 12 & 10 & 09 \\
\hline Staphylococcus aureus & 15 & 22 & 07 \\
\hline Enterococcus faecalis. & 10 & 08 & 13 \\
\hline Proteus mirabilis. & 11 & 15 & 11 \\
\hline Salmonella spp. & 12 & 10 & \\
\hline
\end{tabular}

Table-2. Showing inhibition zone diameter in $\mathbf{~ m m}$. with Ethanol extract.

\begin{tabular}{|l|c|c|c|}
\hline \multirow{2}{*}{ Name of culture } & \multicolumn{3}{|c|}{ Inhibition zone diameter in mm } \\
\cline { 2 - 4 } & \multicolumn{3}{|c|}{ Ethanol extract } \\
\cline { 2 - 4 } & A. sativum & Z. officinale & A. cepa \\
\hline Escherichia coli & 22 & 17 & 16 \\
\hline Klebsiella pneumoniae & 23 & 16 & 15 \\
\hline Pseudomonas aeruginosa & 12 & 10 & 09 \\
\hline Staphylococcus aureus & 15 & 18 & 07 \\
\hline Enterococcus faecalis & 10 & 08 & 13 \\
\hline Proteus mirabilis & 11 & 15 & 10 \\
\hline Salmonella spp. & 13 & 14 & 14 \\
\hline
\end{tabular}


Table-3. Showing inhibition zone diameter in mm. with Aqueous extract.

\begin{tabular}{|l|c|c|c|}
\hline \multirow{2}{*}{ Name of culture } & \multicolumn{3}{|c|}{ Inhibition zone diameter in mm } \\
\cline { 2 - 4 } & \multicolumn{3}{|c|}{ Aqueous extract } \\
\cline { 2 - 4 } & A. sativum & Z. officinale & A. cepa \\
\hline Escherichia coli & 17 & 14 & 13 \\
\hline Klebsiella pneumoniae & 18 & 16 & 11 \\
\hline Pseudomonas aeruginosa & 15 & 19 & 10 \\
\hline Staphylococcus aureus & 19 & 10 & 08 \\
\hline Enterococcus faecalis & 20 & 06 & 05 \\
\hline Proteus mirabilis & 12 & 13 & 09 \\
\hline Salmonella spp. & 10 & 13 & 10 \\
\hline
\end{tabular}

\section{Conclusion}

The present investigation depicts that the chloroform extract of A. sativum is more effective compared to ethanol and aqueous extracts of plants parts used in the present study. The antimicrobial activity of these plant parts indicates there suitability for being used as important composition of certain medicines.

\section{Acknowledgement}

The author is thankful to the Director, Mr. Aasif Zaki and Principal DR. Y.P. Singh of Jawaharlal Nehru college Bhopal M.P. India for providing library and laboratory facilities during this investigation.

\section{References}

[1] Agarwal S.B. 1999. Unified Botany, Shivalal Agarwal \& Company, Agra. P. 167-215.

[2] Ananthnarayan R and Jayaram Panicker C.K.. 1997. Textbook of Microbiology. Orient Longman Lt. Chennai. P. 578-580

[3] Anbuganapathi G., Ponneelan KTPB and Suchitra R. 2002. Antibacterial and Antifungal effect of leaves of Wrightia tinctoria. J. Ecotoxicol. Environ. Monit. 12 (4):299-304

[4] Bauer, A.W., Kirby,W.M.M., Sherris, J.C., Turck, M., (1966). Antibiotic susceptibility testing by a standardized single disk method. Am. J. Clin. Pathol. 45: 493-496.

[5] Bibitha B, Jisha VK, Salitha CV, Mohan S, Valsa AK.2002 Antibacterial activity of different plant extracts. Short Communication. Indian J Microbiol 42: 361-363.

[6] Dubey, R.C. and Maheshwari D.K. 2002. Practical Microbiology S. Chand \& company Lt., New Delhi. P. 154

[7] Elsamma Thomas, Shanmugam T. and Mohamed Rafi M. 1999. In vitro antibacterial activity of certain medicinal plants of Kerala. Biomedicine 19 (3): 185-190.

[8] Hammer, K. A., C. F. Carson and T. V. Rilcy 1999. Antimicrobial activity of essential oil and other plant

[9] Hassawi, D. and Kharma, A., 2006. Antimicrobial Activity of Some Medicinal Plants against Candida albicans. Journal of Biological Sciences.6 (1):109-114.

[10] Kartal, P., Sokemen, A and Sahin, E. 2003. In vitro antibacterial antifungal, and antioxidant activity of the essential oil and methanol extract of herbal part and callus culture of Satureja hortensis, L. Journal of AgricultureFood Chemical, 51 : 3958-3965.

[11] Kelmanson, J.E. and Staden, J.Z., 2000. Medicinal plants with antimicrobial activity. Journal of Ethnopharmacol., 69, 241-246

[12] Malesh, B. and S. Satish 2008. Antimicrobial Activity of some important medicinal plant against plant and human pathogen. World Journal of Agriculture Sciences, 4(5) : 839-843

[13] Mohan M.C.H., Rao, S.M. and Kumari, P 2009. Antimicrobial Activity of Selected Indian Medicinal Plants. Jr. of Microbiol. Biotech. Env.Sc, 11 (2), 355-360.

[14] Muruganandam A.V. and Bhattacharya S.K. 2000. Indole and Flavanoid constituents of Wrightia tinctoria, W. tomentosa and W. coccinea. Ind. J. Chem. 39B (2): 125-131.

[15] Nayak, A., Nayak, R.N, Soumya, B., Bhat K. and Kudalkar, M., 2011. Evaluation of antibacterial and anticandidal efficacy of aqueous and alcoholic extracts of Neem (Azadirachta indica) and in vitro study. IJPAP.1; 230-235.

[16] Parekh, J. and Chanda, S., 2008. In vitro antifungal activity of methanol extracts of some Indian medicinal against pathogenic yeasts and molds. Afr. J. of Biotech.,7(23), 4349-4353

[17] Ramesh A and Hyma B. 1985. Traditional Indian medicine in practice in an Indian Metropolitan city. In: Geographical aspects of wealth and disease in India. Ed: Akhtar R and ATA Learmouth concept publishing company, New Delhi. p. 361.

[18] Shihabudeen,M,S., Hans Priscilla,D and Thirumurugan,K. 2010. Antimicrobial activity and phytochemical analysis of selected Indian folk medicinal plants. Intenational Journal of Pharma Sciences and Research. 10, 430-434. 